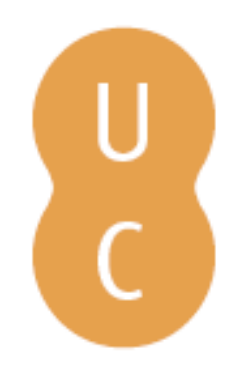

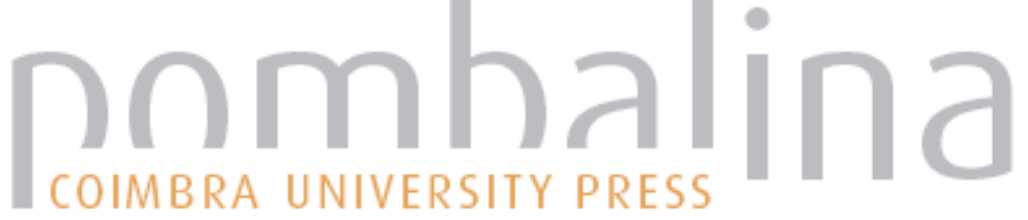

\section{As vinte Cantatas a Dúo (Lisboa, c1724) de Jaime de La Té Y Sagáu}

\author{
Autor(es): $\quad$ Doderer, Gerhard
}

Publicado por: Imprensa da Universidade de Coimbra

URL

persistente: URI:http://hdl.handle.net/10316.2/30041

DOI: $\quad$ DOI:http://dx.doi.org/10.14195/978-989-26-0567-8_11

Accessed : $\quad$ 26-Apr-2023 11:00:04

A navegação consulta e descarregamento dos títulos inseridos nas Bibliotecas Digitais UC Digitalis, UC Pombalina e UC Impactum, pressupõem a aceitação plena e sem reservas dos Termos e Condições de Uso destas Bibliotecas Digitais, disponíveis em https://digitalis.uc.pt/pt-pt/termos.

Conforme exposto nos referidos Termos e Condições de Uso, o descarregamento de títulos de acesso restrito requer uma licença válida de autorização devendo o utilizador aceder ao(s) documento(s) a partir de um endereço de IP da instituição detentora da supramencionada licença.

Ao utilizador é apenas permitido o descarregamento para uso pessoal, pelo que o emprego do(s) título(s) descarregado(s) para outro fim, designadamente comercial, carece de autorização do respetivo autor ou editor da obra.

Na medida em que todas as obras da UC Digitalis se encontram protegidas pelo Código do Direito de Autor e Direitos Conexos e demais legislação aplicável, toda a cópia, parcial ou total, deste documento, nos casos em que é legalmente admitida, deverá conter ou fazer-se acompanhar por este aviso.

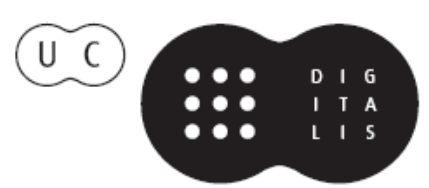




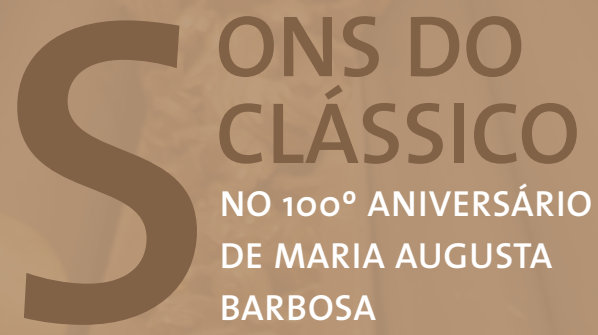

J. M. Pedrosa Cardoso

Margarida Lopes de Miranda COORDENAÇÃO 


\author{
Gerhard Doderer \\ Universidade Nova de Lisboa
}

\title{
AS VINTE CANTATAS A DÚO (LISBOA, c1724) DE JAIME DE LA TÉ Y SAGÁU
}

Enciclopédias portuguesas e espanholas dedicaram, até agora, pouco espaço a Jaime de la Té y Sagáu. ${ }^{86}$ No The New Grove's Dictionary of Music and Musicians expuseram-se ainda todas as notícias reunidas por R. Stevenson; ${ }^{87}$ a edição mais recente ${ }^{88}$ não revelou nada que não tivesse sido publicado pelo autor deste artigo, nomeadamente no prefácio da edição da I Parte das suas Cantatas Humanas. ${ }^{89} \mathrm{O}$ ponto da situação encontra-se resumido na última edição da enciclopédia Die Musik in Geschichte und Gegenwart e, parcialmente actualizada, em trabalhos posteriores de G. Doderer. ${ }^{90}$ Assim, o artigo presente baseia-se na mais recente publicação deste autor do ano de 2012.

86 I. F. da Silva (1858), Diccionario Bibliographico. Lisboa, seg., vol. II, p. 256. - E. Vieira (1900), Diccionario Biographico de Musicos Portuguezes. Lisboa, vol. II, p. 268-269. - Enciclopédia Portugueza Ilustrada, vol. 9, p. 621. - Grande Enciclopédia Portuguesa e Brasileira, vol. 26, p. 604. - E. Casares (ed.) (1986), Francisco Asenjo Barbieri-Biografias y Documentos sobre Música y Musicos Españoles (Legado Barbieri), vol. I, Madrid, pp. 473-474.

87 1980, vol. 18, p. 711.

88 M. C. de Brito (2001), vol. 25, pp. 325-326.

89 G. Doderer (1989), "Jayme de la Té y Sagáu e as suas "Cantatas Humanas" (Lisboa 1715/26)", Revista da Faculdade de Ciências Sociais e Humanas, vol. 3, pp. 141-183; idem (1998), "An unknown repertory of the early 18th-century Iberian "Tonos Humanos/Divinos": The Cantatas of Jaime de la Té y Sagáu (Lisboa, 1715-26)”, M. Boyd, J. J. Carreras (ed.) (1998), Music in Spain during the 18th Century, Cambridge, pp. 80-107; idem (1999) (ed.), Jaime de la Té y Sagáu: Tonos Humanos (Sag: I, 1-40), Parte I, vol. I-II, "Portugaliae Musica", vol. 52, Lisboa.

90 Vol. 18 (suplemento), 2008, col. 922-923; (2009) "Jaime de la Té y Sagau e as suas Cantatas de câmara (1715-1725)", Recerca Musicológica, vol. XIX, pp. 121-133; (2012) "Té y Sagáu's 'Officina da Música' in Lisbon: A Music Printing Enterprise exported from Spain to Portugal?”, B. Lolo, J. C. Gosálvez (ed.), Imprenta y edición musical en España (ss. XVIII-XX), Madrid, pp. 111-130. 
Foi Sousa Viterbo quem, nos seus estudos de 1915 e $1932,{ }^{91}$ se ocupou, pela primeira vez, da obra de Té y Sagáu, sem ligar importância de maior a aspectos musicais. Neste contexto é-nos comunicada a opinião de Francisco Xavier Cavaleiro de Oliveira expressa no ano de 1743 :

... D. Jayme de la Te y Sagau, impressor da Musica na Corte de Lisboa, imprimia estas Décadas [= Décadas da Ásia de Diogo do Couto], porem quando sabi de Portugal creyo que naõ estava feita a obra, e depois disso por falta de correspondencia nã̃ sey se se effeituou, o que duvido, considerado o genio, e a patarata daquelle impressor: por fóra cordas de Violla, por dentro paõ bolorento. ${ }^{22}$

A estas palavras, no entanto, se devem contrapor os versos entusiastas de um outro autor coevo, João Cardoso da Costa que escreveu no Romance XLVII: En applauso de D. Jayme de la Té, Y Sagau, quando compuso en metro, y solfa su libro de Cantatas jocosas, sirviendo tambien de assumpto el Prologo de su libro:

YA con la pluma en la mano

Casi me veo indeciso;

Pues no sê, si alabe el metro,

Ó si la solfa del libro. [...]

[...]

Prueba tanto lo que dize,

Que nó pueden los sentidos

Deshazer con evidencia

Lo que su pluma ha exprimido.

Diganlo tambien los metros,

Lo sonoro, lo melifluo;

Con que gracia los adorna

Lo gracioso de su estilo!

91 F. M. Sousa Viterbo (1915), A Litteratura Hespanbola em Portugal. Lisboa, pp. 399-405; idem (1932), Subsídios para a História da Música em Portugal. Coimbra, pp. 540-542.

92 F. X. Cavaleiro de Oliveira (1743), Memóires Historiques, Politiques et Litteraires, concernant le Portugal, et toutes ses Dependances; avec la Bibliotheque des Ecrivains et des Historiens de ces Etats .... Haia, vol. II, pp. 316-317. 
La solfa une a la letra,

Todo tan bello, y tan lindo,

Que mejor nadie lo hará;

Y tambien yó nò lo he visto.

Vivas mil siglos D. Jayme;

Porque es gloria de los siglos

Eternizares tu nombre

Entre harmoniosos prodigios.

Y la embidia se destierre

Del mundo en sus parocismos,

Pues nó se hallan en todo el mundo

Un Jayme como tu mismo.93

Durante a existência da Officina da Música sairam à luz do dia 395 obras impressas, mais de um terço delas de carácter musical. Assim, as diferentes edições musicais, Libretos, Ceremoniais, Processionais e Tratados litúrgico-musicais representam o conjunto tipográfico mais importante de toda a história da Música portuguesa. Além disso, o contributo do compositor catalão é do maior significado em termos quantitativos e qualitativos para a vida musical palaciana da sociedade joanina, revelando novos parâmetros que devem ser relacionados com a vida musical no reinado de D. João V.

\section{Vida}

Relativamente à biografia de Té y Sagáu, Ann Hatherly, num estudo acerca de uma Alegoria Moral ${ }^{94}$ editada na tipografia de Té y Sagáu, resumiu o resultado das investigações realizadas até 1990, por estudiosos no país e no estrangeiro. Ana Cristina Gonçalves Torres apresentou em 2001 uma magnífica Tese de

93 (1736), Musa pueril. Lisboa, pp. 229-231.

94 A. Hatherly (1990), "A Presioza”, de Sóror Maria do Céu. Edição crítica e comentada do Códice 3773 da Biblioteca Nacional de Lisboa, Lisboa. 
Mestrado sobre a tipografia em questão e revelou muitos dados novos. ${ }^{95}$ Nessa base, e utilizando umas escassas informações transmitidas pelo próprio

Té y Sagáu no Prefácio das Cantatas Jocosas, podemos supor que o poeta, compositor e impressor tenha nascido em Barcelona ${ }^{96}$ a 1 de Setembro cerca de 1684, tomando em conta a observação de Té y Sagáu na sua dedicatória nas mesmas Cantatas Jocosas a D. Jaime de Melo, $3^{\circ}$ Duque de Cadaval, como referência ao dia de nascimento..$^{77}$ No entanto, o ano exacto do nascimento permanece ainda desconhecido. Certo é que foi batizado na freguesia de Santa Maria del Mar, em Barcelona ${ }^{98}$ e que faleceu no dia 31 de Março de 1735 em Lisboa. ${ }^{99}$ Nada consta sobre as circunstâncias da sua morte, sabemos apenas que ficou sepultado no Conventos dos Beneditinos da capital. Graças à documentação elaborada aquando do seu pedido de admissão à Ordem de Santiago, ${ }^{100}$ entendemos que era filho de Jayme de la Té y Sagáu, músico que "cantava por estipendio" e que era, aparentemente, a mesma pessoa que se encontra mencionada várias vezes como harpista da corte, bem como nas atas capitulares da Sé Catedral de Barcelona ${ }^{101}$ nos anos de 1683, 1688 e 1689. $\mathrm{O}$ avô paterno (com o mesmo nome do filho e do neto) era um "dançador" e a sua avó é documentada como tendo sido Úrsula Peinado. Todas estas três pessoas eram naturais do Condado de Ruselhó, Principado da Catalunha.

95 (2001), "A Officina da Musica: uma oficina tipográfica portuguesa da primeira metade do século xviıı", 2 vol. (Faculdade de Ciências Sociais e Humanas, Universidade Nova de Lisboa), Lisboa.

96 “... soy Catalán: ela (= a poesia) nacio en Portugal, yo en Barcelona...”, (Cantatas Jocosas, Libro del Acompañamiento).

97 “... El haver nacido ambos en um mismo dia, aun que con diverso influxo, pudo ser acaso; mas yò lo venero como resolucion del mismo Destino ..." (Libro de la Voz, Dedicatória).

98 Assento do matrimónio, Registos Paroquiais, Freguesia de N. Senhora das Mercês, Casamentos, L. 2, fol. 100.

99 Informação obtida muito recentemente e cedida por A. C. Gonçalves Torres.

100 Mesa da Consciência e Ordens, Secretaria da Mesa e Comum das Ordens, Habilitações da Ordem de Santiago, Letra J, Maço 8, Doc. 5. Este e outros documentos como Carta de padrão, Carta de hábito de noviço, Alvará de Cavaleiro, Alvará de hábito de ouro, Alvará de profissão, Registo de matrimónio, Registos de baptismo dos quatro filhos, Provisão para poder fazer imprimir e vender música encontram-se reproduzidos nas pp. 37 a 79 no mencionado trabalho de A. C. Gonçalves Torres (cf. nota 95).

101 J. Pavia i Simó (1986), La música a la catedral de Barcelona, durant el segle XVIII. Barcelona, pp. 296-297; idem (1990), "La Capella de Música de la Seu de Barcelona des del'inici del s. XVIII fins a la jubilació del Mestre Francesc Valls (14-3-1726)”, Anuario Musical, vol. 45, pp. 17-66, aqui pp. 56-57; idem (1997), La Música en Cataluña en el siglo XVIII - Francesc Valls (1671c. - 1747), Barcelona, p. 35. 
Depois de ter abandonado Barcelona, em 1703, ${ }^{102}$ e passado vários anos em Madrid, ${ }^{103}$ Té y Sagáu chegou, no ano de 1706 ou 1707, à capital portuguesa no séquito do jesuíta e diplomata espanhol D. Álvaro Cienfuegos que se deslocou a Portugal para participar nas negociações do casamento de D. João V com D. Maria Ana de Áustria, casamento que se concretizou em 1708. Sob a proteção desse D. Álvaro viveu Té y Sagáu até ao ano de 1715, altura em que obteve, no dia 12 de Outubro, um privilégio real que lhe concedeu o direito exclusivo de produzir e comercializar edições musicais durante dez anos ("para poder fazer impremir, e vender muzica como se fazia na Corte de Madrid e em todas as mais partes da Europa, e que ninguem senão elle podesse ter a d impreça ̃o"). ${ }^{104}$

Já na altura da sua chegada a Portugal começara a compor cantatas em honra da Rainha D. Maria Ana, como documentam duas cantatas conservadas, em forma manuscrita, na Biblioteca Nacional de Lisboa. ${ }^{105}$ Mais tarde destacou-se, graças às suas composições para as festividades no palácio real (1713, Zarzuela $E l$ poder de la armonía para o aniversário do rei D. João V, texto de Luís Calisto da Costa e Faria) e nas igrejas importantes da capital (Oratória: 1719, Sé Catedral e 1722, Convento da Esperança; Vilancicos vários: 1719 a 1723, Sé Catedral; 1719, 1721-22, Igreja de Santa Justa; 1721-22, Convento da Esperança). ${ }^{106}$ Depois de um processo bastante complicado em que se evocou a falta de condições necessárias, foi devido à intervenção da rainha que Té y Sagáu acabou por ser admitido, em 1715, na Ordem de Santiago. No dia 18 de Setembro de 1715 casou-se na Igreja de N. Senhora das Mercês, em Lisboa, com Anna Jozefa Falcata; testemunhas do casamento foram António

102 J. Dolcet (2006), "El Somni del Parnàs, - La música a l'Acadèmia dels Desconfiats (1700-1705)", Tese de Doutoramento, Universitat Autònoma de Barcelona, p. 59.

103 “... La Corte de Madrid fué mi amado domicilio algunos años; yà son diez y nueve los que existo en Lisboa..", (Cantatas Jocosas, Libro del Acompañamiento). Ver também a Provisão para poder fazer imprimir e vender muzica de 31.10.1715: “... que Jayme de La Te y Sagau caualleiro da ordem de Santiago me reprezentou por sua petição que hauia sete annos que se achaua nesta Corte ...”, Chancelaria de D. João V, L. 46, fol. 78, reproduzido em A. C. Gonçalves Torres, op. cit., p. 79.

104 Ver nota anterior.

105 BNL Reservados, Ms Pombalina 82, fol. 19v-21 e fol. 53v; ver também G. Doderer (1999), Parte I, vol. 1, p. XXIV.

106 Libretos das composições citadas conservaram-se no Rio de Janeiro (Biblioteca Nacional; ver R. E. Horch (1969), Vilancicos da Coleção Barbosa Machado. Rio de Janeiro), Coimbra (Biblioteca Geral da Universidade), Évora (Biblioteca Pública), Vila Viçosa (Biblioteca do Palácio Ducal). Ver A. C. Gonçalves Torres, op. cit., pp. 20-21 e os respectivos números no catálogo ( ${ }^{\text {os }}$ $128,129,130,143,144,147,150,155,156,157,159,161,163,166)$. 
Luís de Sousa, Marquês das Minas, e Diogo de Mendonça, Secretário de Estado. Deste matrimónio nasceram, entre 1716 e 1720, dois filhos e duas filhas; ${ }^{107}$ o seu filho primogénito, Jayme Domingos de la Té y Sagáu, herdou a oficina do pai, e figura ainda no ano de 1736 como editor de uma obra literária, muito embora numa outra oficina tipográfica. ${ }^{108}$ Curiosamente, foi Teotónio Antunes Lima, cujas ligações com Jaime de la Té y Sagáu se desconhecem, que aparece, já em 1736, como proprietário da Oficina da Música. A tipografia chegou a designar-se "Oficina da Música de Teotónio Antunes Lima, Impressor da Sagrada Religião de Malta, debaixo da Protecção dos Patriarcas São Domingos e São Francisco", com atividade comprovada entre 1736 e 1741, sempre no mesmo local, ou seja na Rua da Oliveira ao Carmo. No entanto, não se conhecem obras musicais que tenham sido produzidas nesta tipografia.

Diversas casas impressoras com a designação de "Officina da Música" existiam em Lisboa durante as primeiras décadas do séc. XviII. ${ }^{109}$ Entre elas foi, de longe, a "Imprenta de Música” de Té y Sagáu a mais importante, não só em termos quantitativos como também em relação às espécies que daí saíram durante os dez anos do privilégio concedido em 1715. Em vários casos, Té y Sagáu é apontado como autor, não apenas do texto, mas também da parte musical dos acima mencionados vilancicos que, tal como algumas cantatas, seguiram caminho até à Guatemala onde eram executadas ainda em 1788, de acordo com as indicações que aparecem nos respectivos exemplares da Biblioteca da Sé Catedral da Cidade de Guatemala.

\section{Obra e Edições musicais}

Não podemos estar absolutamente certos ao afirmar que as edições musicais devem ter saído do prelo apenas entre os anos de 1715/16 e 1726; o já

107 Todos os pormenores familiares e a respectiva documentação em C. A. Gonçalves Torres, op. cit., pp. 19-20 e Anexo.

108 A. Hatherly, op. cit.; Stevenson, op. cit.; C. A. Gonçalves Torres, op. cit.

109 "Officina de Musica, Lisboa Ocidental", "Officina Joaquiniana de Música de Bernardo Fernandez Gayo", "Officina de Música de Teotónio Antunes Lima”; ver I. Freire de Andrade (1992), "Impressos musicais em Portugal, do séc. xvi aos fins do séc. xvirl", Actas do Colóquio sobre o Livro Antigo. V Centenário do livro impresso em Portugal 1487-1987. Lisboa, pp. 163-173. 
mencionado privilégio do rei para a "Officina da Musica" fora concedido por um prazo de dez anos mas não é de excluir que uma série de peças compostas por Té y Sagáu tenham sido publicadas já antes de 1715. Além das 12 Cantatas de Emanuele d' Astorga que evidenciam a data de 1726, constituindo a última edição musical da Imprenta de Música de Té y Sagáu, apenas a colectânea das seis "Cantatas a solo al Nacimiento" apresenta uma data (1721). ${ }^{110}$

Hoje podem apontar-se não menos que $253^{111}$ cantatas, sacras e profanas, ${ }^{112}$ com texto em língua castelhana, publicadas, em forma de edições individuais ou em colectâneas, por Té y Sagáu na sua "Imprenta de Música" lisboeta.

A autoria de Té y Sagáu está confirmada, até ao momento presente, para 115 Cantatas Humanas (= cantatas profanas), bem como para seis Cantatas Divinas (= cantatas sacras), em muitos casos também no que diz respeito à origem dos textos. Em relação às restantes composições individuais que figuram nos catálogos que Té y Sagáu, em forma de "Lista de los papeles", inseriu nas suas colectâneas (Partes I a IV) pode assumir-se a autoria do mesmo, apesar de não se terem encontrado, até agora, as peças em causa.

A totalidade destas 253 cantatas divide-se em 87 Cantatas Divinas e em 166 Cantatas Humanas. A par de 167 peças para uma voz e 52 para duas vozes encontramos apenas 14 e 20 composições, respectivamente, a três e quatro vozes. Todas as cantatas são providas de uma parte de acompanhamento em forma de baixo cifrado (Acompañamiento), só algumas poucas vezes foi prevista a entrada de instrumentos de arco com funções solísticas.

110 Esta colecção de Cantatas a solo al Nacimiento é citada por Vieira (1900) que a descreve como abrangendo 37 peças, datada de 1721 e pertencendo, naquela altura, à Biblioteca Pública de Évora. Uma tal colecção, que também Stevenson (1980) menciona da mesma maneira, não se deixou localizar na referida biblioteca.

111 Este número não engloba as seis obras que R. Stevenson (1970, Renaissance and Baroque Musical Sources in the Americas. Washington, p. 100) apresenta no seu catálogo do Arquivo da Sé Catedral da Cidade de Guatemala, uma vez que três destas peças são claramente identificáveis como sendo réplicas das Cantatas Humanas e Divinas indicadas na Lista do próprio Té y Sagáu (IV Parte), ao passo que as restantes três parecem ter sofrido uma substituição do texto original ("Indicios da de la cuna", "Los astros que al reir el alva", "Nace el Rey prometido"). De igual modo não fazem parte do número global das composições impressas as duas cantatas profanas "Ai infelise memoria" e "Despues quel pençamiento que siento" do Ms Pomb 82 da Biblioteca Nacional de Lisboa, fol. 19, fol. 53v; ver também nota 105.

112 Té y Sagáu adoptou para as suas obras a designação "Cantata" ao contrário dos seus colegas do outro lado da fronteira ibérica onde se encontra sempre o termo "Tono"; "Cantata Humana" e "Cantata divina" correspondem, portanto, plenamente aos "Tono Humano" e "Tono divino". 
Como acima mencionado, Té y Sagáu juntou a várias colectâneas das suas cantatas uma "Lista de los papeles", q. d. uma listagem das peças deste género que foram produzidas na sua tipografia em datas anteriores, tanto em forma solta como em coleções encadernadas.

Para facilitar a identificação da obra de Té y Sagáu, reproduziu-se uma listagem resumida das composições que se encontram enumeradas no volume do Baixo contínuo da coleção das Cantatas Jocosas, ou seja da IV Parte das "Cantatas Humanas”, no prefácio da edição moderna da I Parte das Cantatas Humanas a Solo (Lisboa 1999). ${ }^{113}$ Deve tratar-se exatamente das mencionadas Cantatas Jocosas que o autor oferece ao Conde de Unhão no dia 16 de Outubro de 1725, fazendo-as acompanhar de uma carta onde fala do Verão deste mesmo ano como data da publicação. ${ }^{114}$ É de notar que uma das colectâneas com 24 cantatas, ou seja a III Parte, não consta da lista que integra as Cantatas Jocosas, q. d. da IV Parte. Em relação aos Cinquenta minuetes que figuram no fim do catálogo, até hoje nada se chegou a saber.

Té y Sagáu organizou a maior parte das suas composições profanas em séries de colectâneas, facto que garantiu a sobrevivência das cantatas nelas reunidas, o que não aconteceu no caso de peças que saíram à luz isoladamente. 90 Cantatas Humanas, organizadas em colectâneas de 40 (= I Parte), 20 (= II Parte), 12 (= IV Parte) e de 3 x 6 (três coleções de 6) peças conservaram-se nas Bibliotecas de Lisboa, de Évora, de Mafra, de Muge e de Madrid. Através das notas e anotações de F. A. Barbieri ${ }^{115}$ chegou-se a ter conhecimento de uma outra coleção de 24 Cantatas Humanas publicada como III Parte por Té y Sagáu, cujo volume de acompanhamento se conseguiu localizar na Biblioteca Nacional de Madrid, ao passo que a respectiva parte vocal se descobriu, por amável intermédio do Prof. Dr. Antonio Moreno, no Arquivo de Compositores Bascos em Rentería.

Relativamente à datação das colectâneas podemos recorrer ao próprio conjunto das 40 Cantatas Humanas a Solo reeditadas no vol. 52 da Portugaliae

113 A "Lista de los papeles" completa, q. d. com as indicações das partes soltas e dos respectivos preços, tal como aparece nas Cantatas Jocosas (IV Parte) faz parte dos trabalhos citados na nota 89 .

114 Reproduzida em A. C. Gonçalves Torres, op. cit., p. 88.

115 E. Casares (ed.) (1986), Biografías y Documentos sobre Música y Músicos Españoles (Legado Barbieri), vol. 1, Madrid, pp. 473-474. 
Musica, obra dedicada "a la Reyna Nuestra Señora Doña Marianna de Austria". Sem indicação de uma data em concreto, encontra-se apenas mencionada que se tratava de uma "Primera Parte", obviamente na intenção de chamar a atenção ("Se está imprimiendo ùn Libro de Cantatas Humanas á Duo.") para outras (futuras) edições. A proteção de que Té y Sagáu gozava por parte da Rainha, privilégio que esteve naturalmente na origem das palavras afectuosas dirigidas pelo compositor a D. Maria Ana, e o facto de ele ter reunido naquela colectânea um conjunto de cantatas em número que não se deixa explicar por qualquer sentido evocativo ou alegórico, levou-nos à conclusão de que a obra foi oferecida e dedicada à Rainha para festejar os quarenta anos que ela completava no dia 7 de Setembro de 1723. Naturalmente e por razões de delicadeza, a idade da soberana não podia constar da edição, mas a evidência das circunstâncias é tão forte que não hesitámos em apontar exatamente aquela data como o ano da publicação destas 40 Cantatas, já que é pouco lícito pensar que uma tal edição poderia ter sido lançada pelo impressor da corte numa altura que não coincidisse com a celebração festiva do aniversário de D. Maria Ana.

Assumido este facto, podemos deduzir com grande probabilidade que Té y Sagáu deve ter iniciado a sua atividade no campo da impressão musical com inúmeras peças avulsas, tendo procedido apenas no ano de 1721 ao lançamento de cantatas reunidas, primeiramente, em pequenas colectâneas, como p. e. as Cantatas a solo al Nacimiento. O grande número de cantatas sacras listadas pelo impressor e o facto de se encontrar Té y Sagáu mencionado frequentes vezes como autor de vilancicos realizados em igrejas e conventos da capital entre 1719 e 1723, permite também deduzir que o género sacro--litúrgico tinha servido em primeiro lugar para prestigiar o compositor. As outras colectâneas maiores onde se reuniram 20, 24 e 12 cantatas devem ter saído depois de 1723 como Segunda Parte, Terceira Parte e Quarta Parte em ritmo relativamente acelerado, ficando pouco claro se estas composições se encontravam já preparadas em anos anteriores, sempre condicionadas pelo evento do aniversário da Rainha, facto que, naturalmente, não teria permitido avançar com qualquer outro senão com este conjunto de composições designado como Primera Parte. Relativamente à neste trabalho focada Segunda Parte - a única colectânea para duas vozes altas e acompanhamento - é possível 
situá-la, no que diz respeito ao seu lançamento, entre Agosto de $1723\left(40^{\circ}\right.$ aniversário de D. Maria Ana) e o Verão de 1725 (edição da Quarta Parte), constituindo estas datas os termini "post quem" e "ante quem".

\section{As Cantatas Humanas a Dúo}

Na edição original, ${ }^{116}$ as vinte Cantatas Humanas a Dúo foram lançadas em três volumes encadernados em pele (formato oblongo $29 \mathrm{~cm}$ x 20,5 cm), destinando-se os dois primeiros às partes vocais ("Primero Tiple", 112 pág. e “Tiple segundo", 108 pág.) com as seguintes portadas:

CANTATAS / HUMANAS A DUO, / COMPVESTAS / POR DON JAYME DE LA TÊ, Y SAGÂU / Cavallero de la Orden de Santiago. / DEDICADAS / AL SERENISSIMO SEÑOR / DON ANTONIO / INFANTE DE PORTUGAL. / PRIMERO TIPLE. / SEGUNDA PARTE. / [vinheta] / LISBOA OCCIDENTAL. En la Imprenta de Musica, / CON PRIVILEGIO. / Se estan imprimiendo varias obras Divinas, y despues de ellas se imprimirà Tercera Parte de obras Humanas.

CANTATAS / HUMANAS A DUO, / COMPVESTAS / POR DON JAYME DE LA TÊ, Y SAGÂU / Cavallero de la Orden de Santiago. / DEDICADAS / AL SERENISSIMO SEÑOR / DON ANTONIO / INFANTE DE PORTUGAL. / TIPLE SEGUNDO. / SEGUNDA PARTE. / [vinheta] / LISBOA OCCIDENTAL. En la Imprenta de Musica, / CON PRIVILEGIO. / Se estan imprimiendo varias obras Divinas, y despues de ellas se imprimirà Tercera Parte de obras Humanas.

O terceiro serve para a execução do acompanhamento em forma de um Baixo contínuo cifrado (112 pág.), intitulado de maneira muito semelhante:

CANTATAS / HUMANAS A DUO, / COMPVESTAS / POR DON JAYME DE LA TÊ, Y SAGÂU. / Cavallero de la Orden de Santiago. / DEDICADAS /

\footnotetext{
116 Publicação moderna programada para o ano de 2013 (Portugliae Musica, vol. 53, Fundação Calouste Guklbenkian, Lisboa)
} 
AL SERENISSIMO SEÑOR / DON ANTONIO / INFANTE DE PORTUGAL. / ACOMPAÑAMIENTO. / SEGUNDA PARTE. / [vinheta] / LISBOA OCCIDEN-

TAL. En la Imprenta de Musica, / CON PRIVILEGIO. / Se estan imprimiendo varias obras Divinas, y despues de ellas se imprimirà Tercera Parte de obras Humanas. / 6U000.
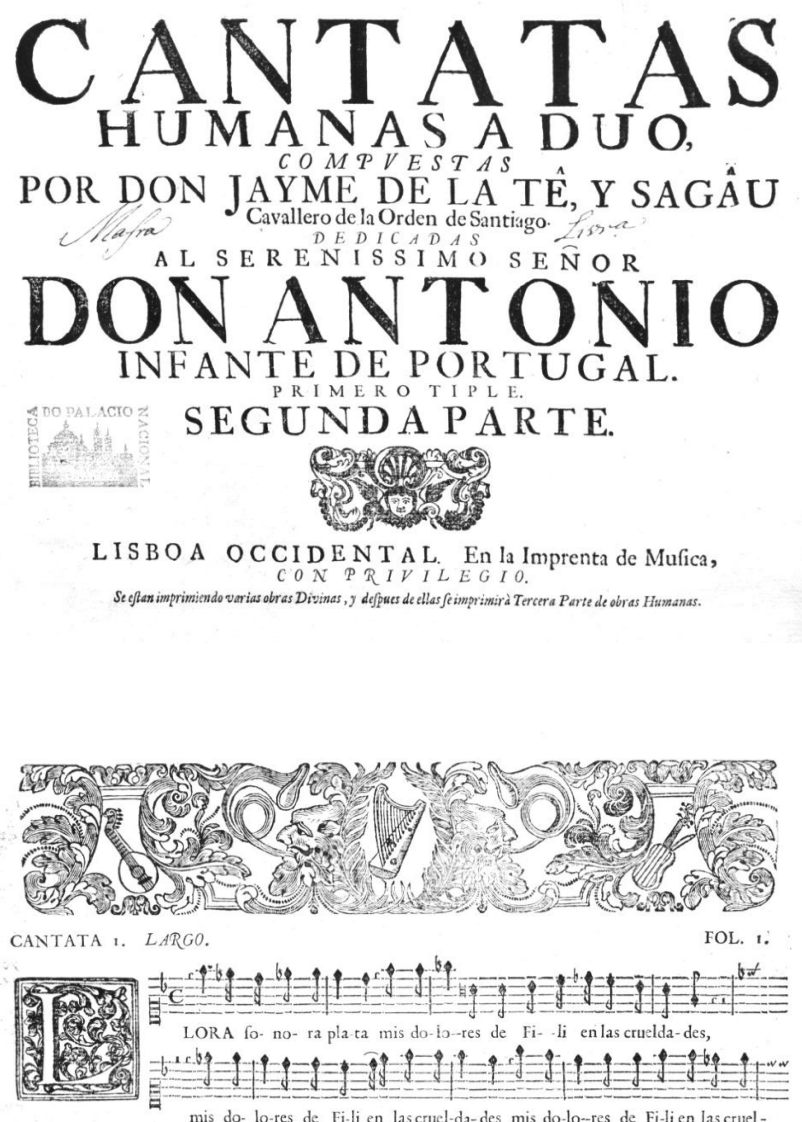
mis do- lo-res de Fi-li en las cruel-da-des mis do-lo--res de Fi-li en las cruel-

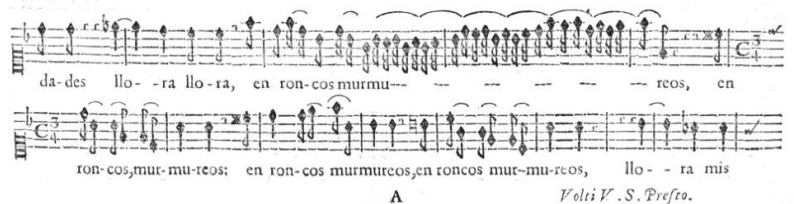

Figura 1 e 2 - Jaime de la Té y Sagáu, Cantatas Humanas a Dúo, Lisboa [c1724], frontispício do volume do Tiple I e início da Cantata I Llora sonora plata 


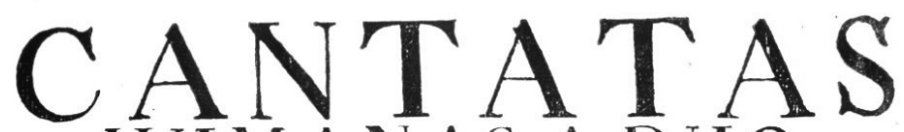

\section{HU M A N A S A DU O,}

POR DON JAYME DE LA TA TE, Y SAGÄU

$D E D I C A D A S$

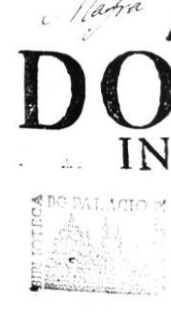

AL SERENISSIMO SENOR

INFANTE DE PORTUGAL.

T I PLE SEGUNDO

SEGUNDA PARTE.

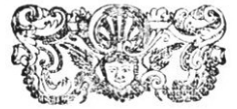

LISBOA OCCIDENT A L. En la Imprenta de Mufica; C $0 N$ P R I V I L E G IO.

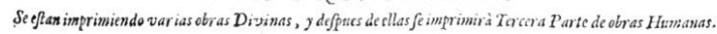
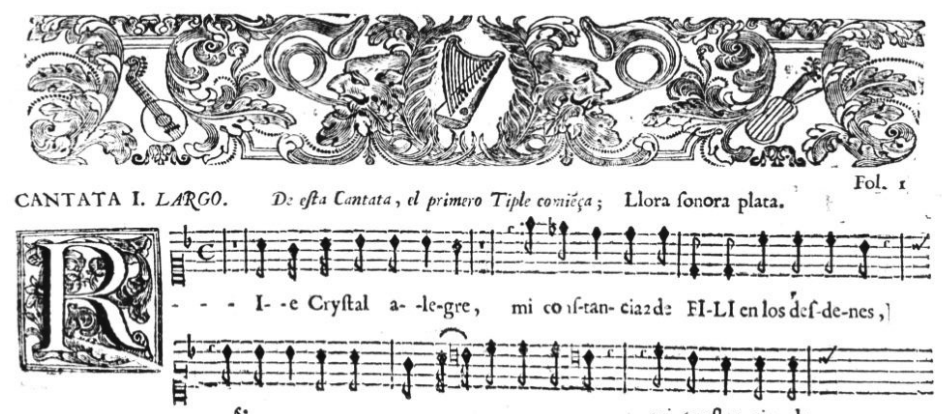

s.

mi conftan-cia de

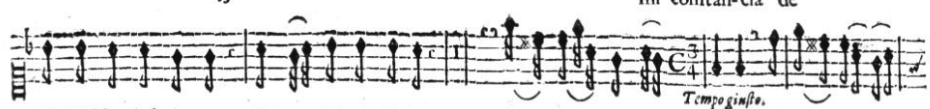

FI-LI é los def-de-nes, Ri-e, Ri-e, Ri-e; En quic-brospe- - renncs, en quicbros pe-

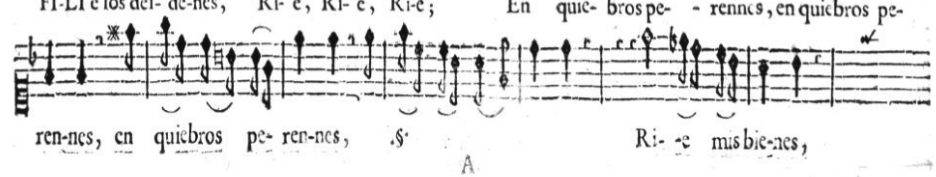

Figura 3 e 4 - Jaime de la Té y Sagáu, Cantatas Humanas a Dúo, Lisboa [c1724], frontispício do volume do Tiple II e início da Cantata I Llora sonora plata 


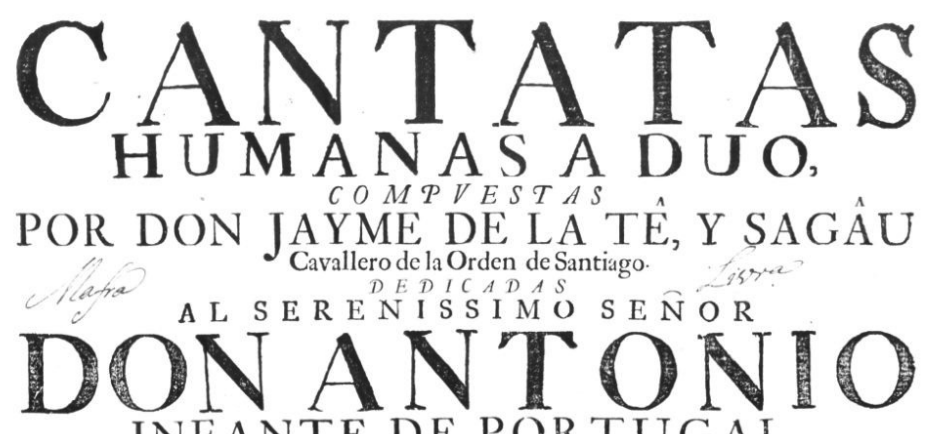

INFANTE DE PORTUGAL.

$A C O M P A \widehat{N} A M I E N T O$

SEGUNDA PARTE.

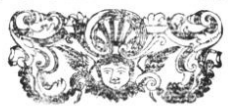

L I B O A O C CI D E N T A L. En la Imprenta de Mufica,

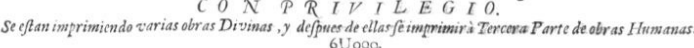

Fol. $x$ :

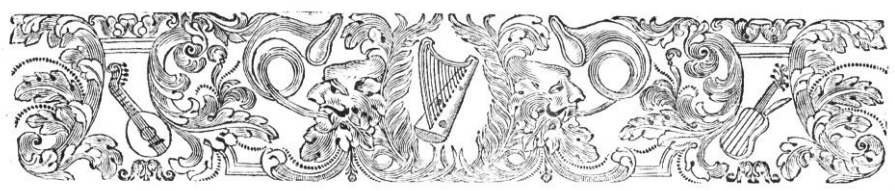

CANTATA I. LARGO. De efta Cantata, el fegunlo Tiple: dize. Rie cryftalalegre,\&c.

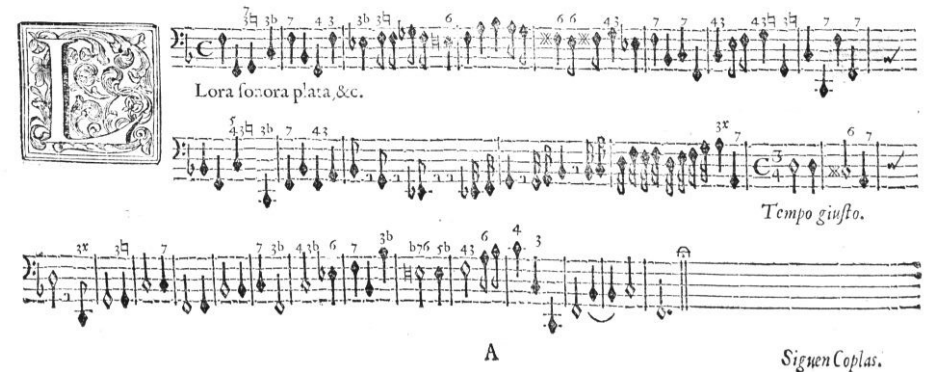

Figura 5 e 6 - Jaime de la Té y Sagáu, Cantatas Humanas a Dúo, Lisboa [c1724], frontispício do volume do Acompañamiento e início da Cantata I Llora sonora plata (Fotografias de G. Doderer com autorização da Biblioteca do Palácio de Mafra) 
Tal como as outras colectâneas de Té y Sagáu, também as Cantatas Humanas a Dúo são dedicadas a uma personalidade da mais alta nobreza portuguesa, no caso presente ao Infante D. António, o irmão mais novo do Rei D. João V. Muito bem conhecido pelas suas inclinações artísticas e capacidades musicais, D. António fez-se notar várias vezes em momentos importantes da vida musical do país, como p. e. aquando da sua deslocação a Itália onde, no ano de 1714, traçou os destinos de Domenico Scarlatti como futuro Mestre de Música do Palácio da Ribeira ${ }^{117}$ (e professor de cravo para si próprio) ou quando estabeleceu contactos vitais na corte do Grão Duque de Florença onde exercia a sua atividade o genial construtor de instrumentos, Bartolomeu Cristofori. É bem significativa a dedicatória que Té y Sagáu dirige a D. António na sua obra, antecipando as palavras apologéticas que, de uma forma bem longe de meras expressões laudatórias subservientes, o real mecenas iria receber no prefácio das famosas primeiras composições para o então novo pianoforte, as Sonate da Cimbalo di Piano e Forte publicadas por Lodovico Giustini di Pistoia em Florença, no ano de $1732 .{ }^{118}$

No volume do acompanhamento das nossas vinte Cantatas Humanas a Dúo encontramos, logo a seguir à portada, um prefácio formulado pelo próprio Té y Sagáu:

Serenissimo Señor,

ESTE Libro de Cantatas á Duo busca con ansia reverente en la Real proteccion de VUESTRA ALTEZA la seguridad, de ser grato á todos. No tube que hazer en la eleccion de Patron tan Soberano, haviendo de darle al publico; pues el esplendor del SERENISSIMO NOMBRE DE VUESTRA ALTEZA illustrando tanto mi idea, que en estos Numeros se representa; basta para hacer, que hasta al vulgo parezca acorde su proporcion, y armonia. Todo este Reyno sabe com admiracion, (y lo van sabiendo los estraños con embidia) que el SERENISSIMO GENIO DE VUESTRA ALTEZA desde sus primeros años empeçò á inclynar su SOBERANA IDEA á la

117 G. Doderer (2009), "Remarks on Domenico Scarlatti's Portuguese Period (1719-1729)" in L. Morales (ed.), Domenico Scarlatti in Spain, Almería, pp. 161-183, aqui pp. 162-163.

118 Cf. G. Doderer (2002), "As Sonatas de Lodovico Giustini di Pistoia, Florença 1732: A Primeira Edição para o Pianoforte" in Lodovico Giustini de Pistoia - Sonate da Cimbalo di Piano e Forte, Rio de Janeiro, pp. 9-27. 
armonia, haviendo empezado Real entretenimiento, lo que oy se venera Magisterio consumado: trasladando á las expressiones del Clavicordio, los conceptos armonicos de la FECUNDA REAL FANTASIA DE VUESTRA ALTEZA con tanto acierto, y destreza en las manos, como si governase cada dedo una inteligencia, y con aquel buen gusto que sabe dar á todas sus acciones un Numen Divino: excediendo venturosamente, lo que por noticia de San Isidro era en la antiguedad documento: pues deseando, que en sus Heroes, por mayor ornato, no se descubriese la torpe ignorancia de la Musica, VUESTRA ALTEZA no solo sabe de esta noble facultad lo que basta para diversion; si no lo que puede servir de enseñanza.

Esta consideracion, y el Real acogimiento que VUESTRA ALTEZA se ba servido hazer á muchas de mis composiciones, dignando-se de entretenerse con ellas algunas horas, me anímam a consagrar, y poner baxo la Soberana inscripcion del SERENISSIMO NOMBRE DE VUESTRA ALTEZA estas Cantatas: y quando careciessen de lo armonioso, nadie podrá negarme, la consonancia que haze esta Dedicatoria con mi esclavitud; y que està muy acorde con mi obligacion mi respeto; pues tambien como en la Musica no puede en el reconocimiento, y veneracion, haver sin distancias armonia. DIOS guarde la SERENISSIMA PERSONA DE VUESTRA ALTEZA, quanto sus criados necessitan.

DON JAYME DE LA TÈ, Y SAGÀU.

Cada um dos três volumes possui um índice com a extensão de duas páginas ("Tabla") inserido depois da portada no caso dos livros dos Tiples e, no volume do Acompañamiento, introduzido a seguir ao prefácio acima reproduzido. Este prefácio é ainda completado por umas listagens das obras publicadas por Té y Sagáu até à altura do lançamento das Cantatas a Dúo. A "Lista de los papeles divinos, y humanos a solo, a duo, a tres, y a quatro con violines, violones, y sin elles ..." enumera os títulos dos "[Tonos] Divinos", ou seja: 25 obras para voz solística, 32 para duas vozes e 18 composições para quatro vozes, naturalmente, todas com acompanhamento. Na secção dos "Humanos" figuram 24 obras a solo, para além de uma menção das Quarenta Cantatas en dos libros [= Parte I], 11 Duos, 3 Tercios e 2 Quatros, seguindo-se uma página com a "Lista de los papeles enquadernados" que abrange 6 Solos 
al Santissimo, 6 Solos al Nacimiento, 3 vezes 6 Solos Humanos e a indicação de Cinquenta Minuetes; no fundo desta mesma página avisa-se que "Se està imprimiendo tercera parte de obras humanas à Solo".

Mas o volume do Acompañamiento ganha ainda uma importância especial devido à reprodução de todos os textos das 20 cantatas da edição (pp. 83 a 112), bem como graças à inserção de umas advertências que dizem respeito à execução do acompanhamento da última Ária da Cantata XX (pág. 82):

Adviertese, ser sumamente difficil (a la primera vista) el Acompañamiento de esta ultima Aria, en qualquiera Instrumento; especialmente en el Arpa, cuya execucion, ès impossible, sin valerse del dedo Anular; pues solo con los otros tres que regular, y generalmente se usan en dicho instrumento, es cansarse en valde pretender executarla. En el Clavicordio, serà algo menos dificil; por raçon de tocarse este instrumento con todos los dedos de ambas manos: y constando los arpeados de esta Aria de quatro notas, aun sobra un dedo para la euxecucion [sic]; pero siempre (por raçon de las distancias) tendrà gran difficultad. En el Violon, serà difficultosissimo; por lo irregular de los trasportes de la mano, sin los quales, no puede haver seguridad en la afinacion, y para conseguir esta (que es el origen de la armonia) es preciso capacitarse de todos los secretos, que encierra en si el Mastil. El estudioso, que a desvelos de su aplicacion los haya adquirido, aun necesitará de un continuo, mental cuydado, para no çoçobrar en el tempestuoso mar de tan successivas dificultades.

No ignoro, ser muy dilatada, y que en mi eleccion estuvo el remedio; pero, advirtiendo que era el ultimo periodo de esta obra, dexè correr la idea quanto quiso, por los campos de la fantasia asta que me pareció justo clausular.

Estas observações são bem esclarecedoras no que diz respeito aos instrumentos que podem servir para a realização do baixo contínuo: o compositor exclui a utilização da harpa a não ser quando se possa empregar a técnica do uso do dedo anelar e coloca grandes reservas relativamente à Viola da Gamba 
(ou ao Violoncelo) devido às dificuldades de afinação, admitindo, no fundo, apenas o cravo ("clavicórdio" conforme a tradicional terminologia castelhana) como meio de concretização satisfatória. É pelo teor da advertência, exclusiva à última Ária da Cantata XX, que ficamos a saber quais os instrumentos que o compositor realmente considera para a execução das suas obras, ou seja harpa, "violón” e cravo. De estranhar é o facto de não estar mencionado o pianoforte apesar das frequentes indicações relativamente a contrastes dinâmicos ("piano", "forte") exigidos ao instrumento destinado a realizar o baixo contínuo.

É também neste mesmo livro do Acompañamiento que aparece, no conjunto dos textos das vinte Cantatas (ver listagem abaixo), a identificação dos autores dos Textos ("Poesias"). Entre eles, dois são responsáveis por três quartos da totalidade dos vinte textos e são-nos conhecidos através da sua colaboração com Té y Sagáu: Julião Maciel, membro do Cabido da Sé Catedral de Lisboa, e Luís Calisto de Costa e Faria - até 1724 funcionário da casa do Visconde de Vila Nova de Cerveira, tendo recebido depois ordens de presbítero do Hábito de S. Pedro - irão ainda contribuir com novas poesias para a Terceira Parte das Cantatas; o último já tinha composto libretos para comédias musicais e zarzuelas representadas na corte lisboeta nos anos de 1712-1713. ${ }^{119}$ Os restantes textos (um deles em anonimato) das Cantatas a Dúo foram atribuídos a Pedro Vaz Rego, mestre reputado da Capela da Sé Catedral de Évora, a Francisco Botelho de Vasconcelos e ao próprio Té y Sagáu.
1. Llora, sonora plata (Texto: Julião Maciel)
2. Nereides bellas (Texto: Francisco Botelho de Vasconcelos)
3. Dulcemente gime (Texto: Pedro Vaz Rego)
4. Quejoso Amor se lamenta (Texto: Julião Maciel)
5. Miró a Matilde el Amor (Texto: Julião Maciel)
6. Tente, arroyuelo infelize (Texto: Julião Maciel)
7. Del rigor de un desvío (Texto: Julião Maciel)

\footnotetext{
119 Fabula de Alfeo y Aretusa, 1712; Son Triunfo de Amor los Zelos, 1712; El Poder de la Harmonia, 1713.
} 
8. Para rendir más suave (Texto: Julião Maciel)

9. Cuando aviva su incendio (Texto: Julião Maciel)

10. ¿Hombres, dónde se albergan compasiones?

(Texto: Luís Calixto de Costa e Faria)

11. Claros arroyos (Texto: Luís Calixto de Costa e Faría)

12. Yo pensé que era alivio (Texto: Julião Maciel)

13. Dulce tirano (Texto: Autor anónimo)

14. Corred, fuentecillas (Texto: Jaime de la Té y Sagáu)

15. Impiedosa beldad (Texto: Luís Calixto de Costa e Faria)

16. Al rigor de una ausencia cruel (Texto: Luís Calixto de Costa e Faria)

17. Juzgaba yo (Texto: Jaime de la Té y Sagáu)

18. Lisonjera inquietud (Texto: Luís Calixto de Costa e Faria)

19. De Amor, en el mar (Texto: Luís Calixto de Costa e Faria)

20. Estrella enemiga (Texto: Luís Calixto de Costa e Faria)

\section{Forma e estrutura das Cantatas}

Entre as particularidades musicais e formais das Cantatas Humanas deve apontar-se, em primeiro lugar, a sequência dos andamentos que, de forma alguma, se demonstra minimamente normalizada. O esquema estrutural é quase sempre variado, tanto em termos numéricos como em termos de combinação sequencial, e tem como elementos constituintes Árias, Recitativos e Coplas, para além de secções formalmente menos definidas, designadas de Prelúdio, Introdução ou apenas com o carácter do Andamento (p. e. Grave, Larguissimo, etc.). Numa combinação sequencial totalmente livre encontram-se cantatas com apenas dois andamentos ao lado de outras com oito. No entanto, a Ária e o seu antecedente Recitativo parecem constituir, de acordo com o omnipresente modelo italiano do fim do séc. XVII/princípio do séc. XVIII um tipo de "módulo base" que é alargado através de duplicações ou até triplicações (R1-A1-R2-A2 ou R1-A1-R2-A2-R3-A3); este esquema enriquecido 
fica sujeito, por sua vez, a uma série de diferentes processos de variação formal, processos que incluem substituições e aumentos por meio de outras secções formais. Neste contexto, é atribuído às Coplas um papel de grande importância, pois servem não apenas como elemento estrutural, quase aleatório em termos da sua colocação múltipla (inicial, central ou final), mas também como tradicional reminiscência formal que evoca, a todo o momento, a vivência das estrofes do Vilancico.

Com esta surpreendente liberdade estrutural contrasta uma fascinante tendência para criar determinadas áreas formais que ultrapassam, em aspectos conceituais, todos os outros andamentos. Nas Árias, Té y Sagáu pouco ou nada se afasta do $D a$ Capo habitual, atribuindo à primeira parte uma clara e muitas vezes desequilibrada preponderância dimensional em desfavor da segunda parte. Para além da sua múltipla inserção entre os outros andamentos das cantatas, as Coplas apresentam-se às vezes com uma secção final transitória, semelhante a um recitativo, particularidade que juntamente com ocasionais familiaridades motívicas em relação às secções antecedentes - evidencia o intuito de alcançar uma maior unidade do conjunto da peça. No já referido afastamento do modelo tradicional, devido à introdução e entrelaçamento de andamentos ou secções mais complexas, onde se sucedem, em semelhança à construção do Moteto, diversas mini-secções de caracter arioso e recitado (divergentes em termos de "afectos musicais", de pulsações e movimentações rítmicas e de contornos melódicos), pode reconhecer-se a intenção do compositor de criar momentos de uma expressão dramática mais abrangente, afastando-se do rigor formal das tradicionais "árias de número" barrocas. Neste sentido não é de estranhar que as extensões globais das cantatas, abrangendo p. ex. no caso das nossas Cantatas Humanas a Dúo peças de 189 a 529 compassos, nem sempre possam ser sintomáticas para a existência de poucos ou muitos andamentos; assim, verificamos cantatas com seis ou sete secções (andamentos) e apenas 169 a 187 compassos, respectivamente, e, por outro lado, obras com três andamentos que atingem os 422 compassos.

No quadro anexo oferece-se uma visão clara em relação aos andamentos e às estruturas destas Cantatas, bem como relativamente à sua construção tonal, aos números de compassos e à configuração rítmica. 


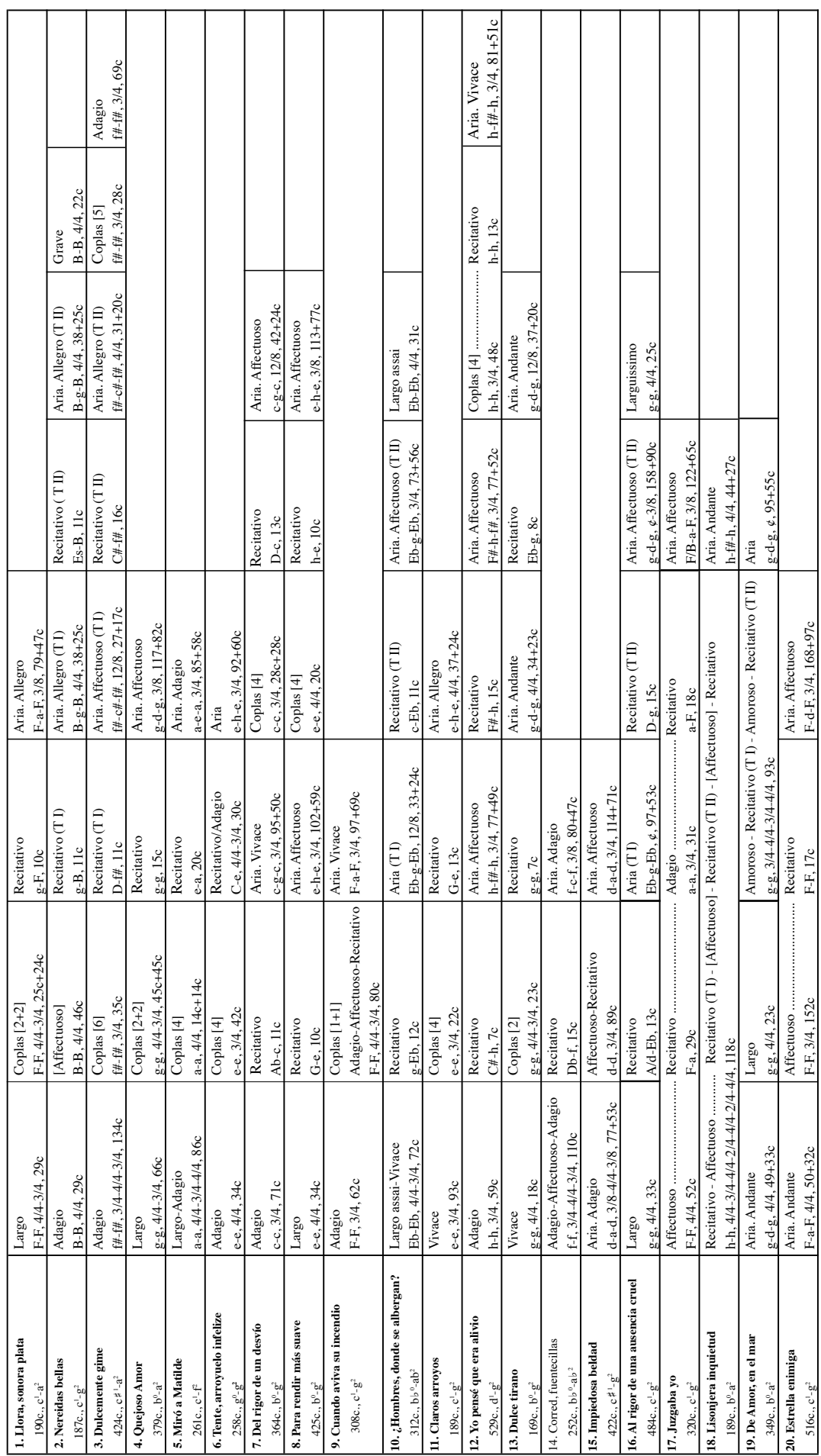


Té y Sagau deve ter encontrado a inspiração para proceder desta maneira não tanto nas cantatas de Scarlatti, Bononcini ou Händel, mas antes e de uma forma bem evidente na construção estrutural dos Tonos Humanos, em voga nos anos de ca. de 1700, da autoria de Pedro Rabassa, Francisco Valls, Sebastián Durón, José Torres e Antonio Literes, ou seja de compositores ligados a Valencia, Barcelona e à Capela real de Madrid. ${ }^{120}$

\section{Linguagem idiomática}

Tanto as quarenta Cantatas Humanas da I Parte, como os vinte Cantatas Humanas a Dúo da II Parte evidenciam uma série de particularidades idiomáticas, quer no seu conjunto quer também nas suas ocorrências isoladas. A Cantata de Câmara da época de Té y Sagáu, um género musical bem cultivado e omnipresente nos salões da alta sociedade barroca, circulava em moldes que tinham recebido um cunho próprio graças a autores como Alessandro Scarlatti, Giovanni Bononcini ou Emanuele d' Astorga, e oferecia, para além disto, grande flexibilidade e abertura em termos formais e estilísticos, factos que a tornaram bem atraente para os compositores meridionais. Foi certamente este último factor razão muito forte para o nosso compositor, pois que se verifica nas mencionadas obras uma variedade de elementos formais e musicais, de forma tal que a sensação de coerência conjuntural das duas colectâneas se obtém mais sob o aspecto literário do que sob o aspecto musical.

O texto em língua castelhana evoca muitas vezes o ambiente pastoril com personagens mitológicas e alegóricas, estando sempre presente o sofrimento e o tormento amorosos originados pela crueldade da figura amada que provoca assim a infelicidade do poeta. Embora condicionado pelas convenções da lírica barroca em uso na sociedade joanina daqueles anos, Té y Sagáu consegue encontrar muitas vezes imagens e descrições onde transpiram

120 J. J. Carreras (1997), "La cantata de cámara española de principios del siglo XVIII: El manuscrito M 2618 de la Biblioteca Nacional de Madrid y sus concordancias”. In María Antonia Virgili Blanquet, Germán Vega Garcia-Luengos, Carmelo Caballero Fernández-Rufete (ed.), Música y literatura en la península ibérica: 1600-1750. Valladolid, pp. 65-126; idem (1998), "Spanish cantatas in the Mackworth collection at Cardiff". In M. Boyd, J. J. Carreras (ed.), Music in Spain during the Eighteenth Century, pp. 108-122; idem (2001), "Cantata, V: The Spanish cantata to 1800", The New Grove Dictionary of Music and Musicians, vol. 5, pp. 37-40, aqui pp. 38-39. 
sentimentos sinceros e humanos, não deixando de lado evocações humorísticas. A preferência por este género de tema literário irá refletir-se, mais tarde e durante muitas décadas, nos milhares de versos das Modinhas dos compositores portugueses e brasileiros dos séculos XVIII e XIX.

Té y Sagáu atinge uma considerável força de expressão musical personalizada no campo das linhas melódicas que, a miúdo, fazem lembrar as de Pergolesi e Händel. Temas e motivos evidenciam uma tendência para ficarem reduzidos e encurtados no decorrer dos andamentos e afinidades melódicas entre os motivos principais dos vários andamentos das cantatas são relativamente frequentes. Sempre concebidas em íntima relação com a métrica e a acentuação da poesia, as melodias das Cantatas Humanas a Dúo foram construídas com vigor e flexibilidade, ricas em espontaneidade insinuante, entrando facilmente no ouvido. Para além de uma cuidadosa periodização, quase sempre marcada em unidades de quatro compassos com as suas respectivas divisões e duplicações, as linhas melódicas de Té y Sagáu caracterizam-se por uma morfologia que corresponde ao conteúdo do texto, recorrendo, em termos iguais, a fórmulas curtas ou ao encadeamento de um considerável número de grupos de colcheias ou semicolcheias, a saltos (até ao intervalo de nonas) ou a progressões em graus conjuntos. As partes vocais contemplam para o Tiple e o Contralto a extensão de sol $^{0}$ até ao lá ${ }^{2}$. Sequências são bem frequentes mas não utilizadas em excesso, sendo normalmente duas repetições do motivo em causa consideradas suficientes para sublinhar duplicações de frases parciais do texto. Nas obras para duas vozes nota-se uma tendência para quadruplicar o número de motivos sequenciais, obviamente com a finalidade de obter, através da repetição em duplicado, o efeito de eco ou de "pergunta-resposta". As linhas melódicas ajeitam-se sempre à textura literária, nunca admitindo qualquer discrepância entre ambas no que diz respeito à acentuação, mesmo quando as frases se apresentam em fragmentos ou nas repetições de palavras. Em muitos casos, palavras realçadas e apresentadas várias vezes encontram novas colocações dentro das unidades métricas, sem perder, no entanto, a sua acentuação literariamente correta.

Tanto nas Cantatas para uma voz como para duas vozes e acompanhamento deve ser sublinhado o papel particular do Baixo contínuo com as antecipações motívicas nos inícios dos andamentos e das diferentes secções, 
constituindo-se não apenas como base harmónica omnipresente mas também como parceiro complementar no enredo imitativo das vozes. Tiple I e Tiple II /Contralto apresentam desenhos motívicos que se baseiam em pré-imitação e imitação regular, formação em pares, cruzamento das vozes e alternância entre condução sucessiva-imitativa e paralela. Figuras rítmicas, hemiolização, "wordpainting" e o rico repertório de figuras da "Affektenlehre" caracterizam incessantemente a escrita de Té y Sagáu.

Relativamente ao conteúdo musical e à sua configuração artístico-expressiva observa-se uma certa irregularidade nos patamares qualitativos, tanto no que diz respeito à colecção na sua globalidade como também quanto aos andamentos que constituem o conjunto de cada uma destas Cantatas: peças extremamente bem conseguidas alternam com outras menos entusiasmantes e várias das Cantatas surpreendem-nos devido ao contraste entre os seus andamentos, uns à altura dos grandes mestres da época e outros sem notável inspiração ou brilhantismo. Nota-se uma maior e quase espontânea leveza de expressão musical na forma como o compositor formula o ductus musical e harmónico quando se trata de tonalidades menores que ultrapassam, numericamente, as tonalidades maiores, facto que se pode observar também na obra de alguns outros compositores lusos ativos na mesma época em que as Cantatas de Té y Sagáu foram concebidas.

\section{Madrid - Lisboa}

Por enquanto, de nenhuma documentação dispomos que nos possa esclarecer relativamente à relação direta de Té y Sagáu com Madrid, ou seja com as pessoas da Capela Real e, em primeiro lugar, com José Torres Martinez Bravo. ${ }^{121}$ As suas declarações sobre a estadia em Madrid são mais que escassas mas é mais que evidente que a Imprenta de Música de Torres que tinha iniciado as suas atividades em 1699 com a publicação dos Destinos vencen finezas, da autoria de Juan de Navas, serviu de modelo e inspiração comercial

121 B. Lolo (2001), "Torres y Martínez Bravo, Joseph de". In: The New Grove Dictionary of Music and Musicians, vol. 25, pp. 635-637.; idem (2002), "Torres y Martínez Bravo, Joseph de". In: Diccionario de la Música Española e Hispanoamericana. [Madrid], vol. 10, 2002, pp. 409-42. 
e artística para o jovem Catalão. Ao começar a produzir música impressa para os músicos lisboetas, Té y Sagáu seguiu obviamente os parâmetros que encontrara em Madrid para as edições de peças de menor porte, tanto no que respeita ao formato do papel e à apresentação dos frontispícios como à organização dos textos musicais. Se bem que as características comerciais e conceituais da sua Oficina se assemelhassem muitíssimo às da Imprenta de Música madrilena, as edições musicais propriamente ditas não podiam assumir as mesmas dimensões e - intencionalmente - abranger os mesmos géneros musicais. ${ }^{122}$ Às composições impressas durante o período do privilégio concedido, procurou-se conferir um alto nível de qualidade gráfica; todo o tipo de pautas, de caracteres musicais e das cifras das partes de acompanhamento distingue-se claramente do material utilizado por Torres em Madrid. Salta à vista que o conjunto dos elementos do grafismo musical e a sua configuração em geral aparenta uma grande semelhança com a célebre edição das Flores de Musica de Manuel Rodrigues Coelho, produzida em Lisboa por Pedro Craesbeeck no ano de 1620. Futuras pesquisas hão-de fornecer mais clareza sobre este ponto, como se deve esclarecer, também, até que ponto um hipotético relacionamente entre Té y Sagáu e José Torres justifica apontar uma exportação de um modelo ou de um projecto de Madrid para Lisboa; certo é que houve uma transferência de conceitos e tecnologia, uma "transplantação" de uma árvore ainda bem tenra que, no entanto, cresceu, ramificou e deu muito fruto em terras lusitanas.

\section{Conclusão}

Durante a existência da Officina de Música na propriedade de Té y Sagáu sairam à luz do dia 395 obras impressas, 42,8\% delas de carácter musical. Assim, as Cantatas Humanas - e entre elas as vinte Cantatas Humanas a Dúo como expoentes máximos - e as outras edições musicais, bem como os Libretos, Ceremoniais, Processionais e Tratados litúrgico-musicais representam o

122 B. Lolo (1988), La Música en la real Capilla de Madrid: José de Torres y Martinez Bravo (b. 1.670-1.738). Madrid, pp. 101-126. 
conjunto tipográfico mais importante de toda a história da Música portuguesa. Além disso, o contributo do compositor catalão é do maior significado em termos quantitativos e qualitativos para a vida musical palaciana da sociedade joanina, revelando novos parâmetros com os quais se deve identificar a vida musical no reinado de D. João $\mathrm{V}$, em relação à qual se tem negado, até há pouco e de maneira quase absoluta, aspectos relevantes de carácter profano.

\section{Bibliografia}

Costa, J. Cardoso (1736), Musa pueril. Lisboa.

Carreras, J. J. (1997), "La cantata de cámara española de principios del siglo XVIII: El manuscrito M 2618 de la Biblioteca Nacional de Madrid y sus concordancias", in María Antonia Virgili Blanquet, Germán Vega Garcia-Luengos, Carmelo Caballero Fernández-Rufete (ed.), Música y literatura en la península ibérica: 1600-1750. Valladolid, pp. 65-126.

(1998), "Spanish cantatas in the Mackworth collection at Cardiff", in M. Boyd, J. J. Carreras (ed.), Music in Spain during the Eighteenth Century, Cambridge, pp. 108-122.

E. Casares (ed.) (1986), Francisco Asenjo Barbieri - Biografias y Documentos sobre Música y Musicos Españoles (Legado Barbieri). Madrid.

Doderer, G. (1989), "Jayme de la Té y Sagáu e as suas "Cantatas Humanas" (Lisboa 1715/26)", Revista da Faculdade de Ciências Sociais e Humanas, vol. 3, pp. 141-183.

(1998), "An unknown repertory: The Cantatas of Jaime de la Té y Sagáu (Lisboa, 1715-26)" in M. Boyd, J. J. Carreras (ed.) (1998), Music in Spain during the 18th Century, Cambridge, pp. 80-107.

(1999), Jaime de la Té y Sagáu: Tonos Humanos (Sag: I, 1-40), Parte I, "Portugaliae Musica", vol. 52, Lisboa.

(2002), "As Sonatas de Lodovico Giustini di Pistoia, Florença 1732: A Primeira Edição para o Pianoforte" in Lodovico Giustini de Pistoia - Sonate da Cimbalo di Piano e Forte, Rio de Janeiro.

Dolcet, J. (2006), "El Somni del Parnàs, - La música a l'Acadèmia dels Desconfiats (1700-1705)", Tese de Doutoramento, Universitat Autònoma de Barcelona.

Hatherly, A. (1990), "A Presioza”, de Sóror Maria do Céu. Edição crítica e comentada do Códice 3773 da Biblioteca Nacional de Lisboa, Lisboa.

B. Lolo (1988), La Música en la real Capilla de Madrid: José de Torres y Martinez Bravo (b. 1.670-1.738). Madrid

Oliveira, F. X. Cavaleiro de (1743), Memóires Historiques, Politiques et Litteraires, concernant le Portugal, et toutes ses Dependances; avec la Bibliotheque des Ecrivains et des Historiens de ces Etats .... Haia. 
Pavia i Simó, J. (1986), La música a la catedral de Barcelona, durant el segle XVIII. Barcelona.

(1990), "La Capella de Música de la Seu de Barcelona des del'inici del s. XVIII fins a la jubilació del Mestre Francesc Valls (14-3-1726)", Anuario Musical, 45, pp. 17-66.

(1997), La Música en Cataluña en el siglo XVIII - Francesc Valls (1671c. - 1747), Barcelona.

Viterbo, F. M. Viterbo (1915), A Litteratura Hespanhola em Portugal. Lisboa.

(1932), Subsídios para a História da Música em Portugal. Coimbra.

Torres, A. C. Gonçalves (2001), "A Officina da Musica: uma oficina tipográfica portuguesa da primeira metade do século xvıI", Tese de Mestrado, Faculdade de Ciências Sociais e Humanas/Universidade Nova de Lisboa, Lisboa. 